\title{
CORRECTION
}

\section{Correction to: Characteristics, decoupling effect, and driving factors of regional tourism's carbon emissions in China}

\author{
Guobao Xiong ${ }^{1,2} \cdot$ Junhong Deng ${ }^{1} \cdot$ Baogen Ding ${ }^{1}$
}

Published online: 23 February 2022

๑) Springer-Verlag GmbH Germany, part of Springer Nature 2022

\section{Correction to: Environmental Science and Pollution Research https://doi.org/10.1007/s11356-022-19054-9}

In Figure 3c, the label should be 2015 2019.

The Original article has been corrected.

Publisher's Note Springer Nature remains neutral with regard to jurisdictional claims in published maps and institutional affiliations.

The original article can be found online at https://doi.org/10.1007/ s11356-022-19054-9.

Junhong Deng

dengjunhong_a@163.com

1 Research Center of Resource and Environmental Economics, East China University of Technology, Nanchang 330013, China

2 Resource and Environmental Strategic Soft Science Research Base of Jiangxi Province, Nanchang 330013, China 